\title{
The value of the middle cerebral to umbilical artery doppler ratio in the prediction of neonatal outcome in patients with high risk pregnancy
}

\author{
Ramkanwar Deora, Nikhila Gara*
}

Department of Obstetrics and Gynecology, Ummaid Hospital, Dr. SNMC Medical College, Jodhpur, Rajasthan, India

Received: 27 June 2017

Revised: 22 July 2017

Accepted: 25 July 2017

\section{*Correspondence:}

Dr. Nikhila Gara,

E-mail: nikhilag78@gmail.com

Copyright: (c) the author(s), publisher and licensee Medip Academy. This is an open-access article distributed under the terms of the Creative Commons Attribution Non-Commercial License, which permits unrestricted non-commercial use, distribution, and reproduction in any medium, provided the original work is properly cited.

\begin{abstract}
Background: To investigate the diagnostic value of MCA/UA pulsatility index ratio for the prediction of adverse perinatal outcome in patients with high risk pregnancy.

Methods: We included in the study 170 patients recovered in our hospital with the diagnosis of preeclampsia and gestational hypertension, twins, postdated, IUGR, BOH from June 2016 to May 2017. All the patients underwent accurate color Doppler velocimetry examination available in our hospital. Outcome variables were intrauterine and early neonatal death, admission to neonatal intensive care unit and the duration of treatment, APGAR score below 7 at 5 minutes, cesarean delivery for foetal distress, gestational age at delivery, neonatal birth weight, IUGR.

Results: In 102 patients, we found abnormal values of CPI ratio. Neonates of mothers with abnormal CPI ratio had significantly lower gestational age at delivery, lower birth weight, significantly greater risk for perinatal death, significantly greater risk of admission to intensive care unit, longer duration of treatment in NICU, greater rate of cesarean delivery for foetal distress, increased number of fetuses IUGR.

Conclusions: CPI ratio is a very good predictor of adverse outcome in the fetuses of women with pre-eclampsia and other high-risk pregnancy.
\end{abstract}

Keywords: Middle cerebral artery, Pre- eclampsia, Umbilical artery

\section{INTRODUCTION}

Preeclampsia affects $5-10 \%$ of pregnancies and is a major cause of maternal and fetal morbidity and mortality. ${ }^{1,2}$ Although there is no proven effective method for the prevention of the preeclampsia, routine antenatal care has the aim to identify women who are at risk for intensive antenatal care. Abnormal placentation is a main preeclampsia characteristic. Its cause is a maternal spiral veins trophoblastic invasion failure, which conditions vascular resistances raise and uterus placental perfusion decrease. Satomura demonstrated that the Doppler technique could evaluate blood flow. ${ }^{3}$ Nowadays, Doppler ultrasound velocimetry of uteroplacental umbilical and fetal vessels has become established method of antenatal monitoring, allowing the noninvasive assessment of fetal circulation. ${ }^{4}$ Its indices provide important information on the hemodynamics of the vascular area under study. ${ }^{5}$ Circulatory changes, reflected in certain fetal Doppler waveforms, predict adverse perinatal outcome. ${ }^{6}$ Umbilical arteries are the common vessels assessed by Doppler ultrasound, but recent studies confirm the efficacy of middle cerebral artery (MCA) Doppler assessment and advocate it. ${ }^{7,8}$ MCA Doppler measurement is a well-known modality for detecting fetal compromise. ${ }^{9}$ Some studies has showed that MCA blood flow abnormalities were associated with hypoxia. ${ }^{1,8,10}$ Adverse perinatal outcome. 
Relationship between fetal Doppler findings and perinatal risks has been defined in numerous cross-sectional studies. ${ }^{11}$ Several studies have reported higher sensitivities and specificities for middle cerebral artery/umbilical artery (MCA/UA) Doppler ratio compared with umbilical artery velocimetry alone for the prediction of the fetal prognosis. ${ }^{12-15} \mathrm{MCA} / \mathrm{UA}$ ratio reflects not only the circulatory insufficiency of the umbilical velocimetry of the placenta manifested by alterations in the umbilical S/D ratio but also the adaptive changes resulting in modifications of the middle cerebral S/D ratio. ${ }^{12}$ In this study, we evaluated the predicting value of the MCA/UA ratio, for fetal prognosis in women with gestational hypertension and preeclampsia, twin pregnancy, $\mathrm{BOH}$, post-dated pregnancy.

\section{METHODS}

The study group consisted of 170 women admitted to OBG Dept, Ummaid Hospital, Jodhpur from June 2016 to May 2017. All patients had undergone serial color Doppler ultrasound. The Umbilical Artery color Doppler waveforms were obtained from a free-floating portion of the umbilical cord during minimal fetal activity and the absence of fetal breathing. All measurements were performed in the semi-recumbent positions with the head and chest slightly elevated. Doppler signals were recorded with a $3.5 \mathrm{MHz}$ curved array duplex transducer. The UA pulsatility index were considered abnormal when the values were $>2 \mathrm{SD}$, the MCA pulsatility index was considered abnormal when the values were $<5^{\text {th }}$ percentile. MCA/UA PI <1 was considered abnormal. ${ }^{16}$ The reference values are according to Gramellini et al. ${ }^{17}$ Major adverse perinatal outcome were stillbirth and neonatal death. Minor adverse perinatal outcome was cesarean delivery for fetal distress, admission to the neonatal intensive care unit, Apgar score below 7 at 5 minutes, IUGR fetuses. The gestational age of all women was confirmed, either by menstrual dates or by first trimester ultrasonography. Preeclampsia patients included thone who had a mild (systolic blood pressure $>140$ $\mathrm{mmHg}$, diastolic $>90 \mathrm{mmHg}$ and proteinuria $300 \mathrm{mg} / 24 \mathrm{~h}$ or $=+1$ dipstick) or severe preeclampsia (systolic blood pressure $>160 \mathrm{mmHg}$, diastolic $>100 \mathrm{mmHg}$ and severe proteinuria $2 \mathrm{~g} / 24 \mathrm{~h}$ or +2 dipstick). The diagnosis of gestational hypertension was made in women whose blood pressure reached 140/ $90 \mathrm{mmHg}$ or greater for the first time during pregnancy but in whom proteinuria was not developed. ${ }^{18}$ Women with twin pregnancies, chromosomal abnormalities, gestational diabetes, were included in the study. Those included were followed by periodical Doppler flow measurements at least one time per week measurements until delivery. ${ }^{19-24}$

\section{RESULTS}

Doppler velocimetry studies of placental and fetal circulation can provide important information regarding fetal well-being, yielding an opportunity to improve fetal outcome. Our results suggested that the MCA/UA PI
Doppler ratio of less than 1 was a good predictive tool for neonatal outcome in preeclamptic and hypertensive pregnant women and could be used to identify fetuses at risk of morbidity and mortality. The use of Doppler ultrasound in high-risk pregnancies appears to improve a number of obstetric care outcomes and promising in reducing perinatal deaths.

Fetuses with abnormal Doppler MCA/UA PI ratio in our study had a significantly lower birth weight, lower gestational age at delivery, 1 significantly higher incidence of perinatal deaths, higher incidence of admission to NICU and longer duration of treatment there, lower Apgar score at 5-minute.

Table 1: Table showing type of delivery.

\begin{tabular}{|ll|}
\hline Type of delivery & No. of cases \\
\hline Vaginal & 96 \\
\hline Caesarean & 74 \\
\hline
\end{tabular}

Table 2: Table showing risk factors.

\begin{tabular}{|l|l|}
\hline Risk factors & No. of cases \\
\hline PIH & 56 \\
\hline IUGR & 29 \\
\hline PIH+IUGR & 44 \\
\hline BOH & 18 \\
\hline Twins & 14 \\
\hline Post dated & 9 \\
\hline
\end{tabular}

Table 3: Table showing risk factors and doppler abnormal.

\begin{tabular}{|lll|}
\hline Risk factors & $\begin{array}{l}\text { Normal } \\
\text { doppler }\end{array}$ & $\begin{array}{l}\text { Abnormal } \\
\text { doppler }(\mathrm{CPI}<\mathbf{1}\end{array}$ \\
\hline PIH & 34 & 22 \\
\hline IUGR & 16 & 13 \\
\hline PIH+IUGR & 26 & 18 \\
\hline BOH & 12 & 6 \\
\hline Twins & 13 & 1 \\
\hline Post dated & 6 & 3 \\
\hline
\end{tabular}

Table 4: Table showing perinatal outcome.

\begin{tabular}{|l|l|}
\hline Perinatal outcome & No of cases \\
\hline Low birth weight & 76 \\
\hline Poor Apgar Score & 42 \\
\hline Hypoxic ischemic encephalopathy & 12 \\
\hline Meconium aspiration & 32 \\
\hline NICU admission & 88 \\
\hline Neonatal deaths & 4 \\
\hline Stillbirth & 3 \\
\hline
\end{tabular}

Brar et al recognized that Doppler studies of the internal carotid artery or a ratio of cerebral to umbilical resistance could be used to identify pregnancies with a compromised post-date fetus. ${ }^{25}$ The fetuses in our study 
with adverse outcome had a lower middle cerebral artery PI index, supporting the finding of Brar et al.

According to Gramellini et al. and Arduini et al, assessment of MCA/UA PI index provide better information in pre-dicting perinatal outcome when compared with umbilical or middle cerebral artery Doppler indices alone. ${ }^{17,26}$ In our study, we found high sensitivity of the MCA/UA PI ratio in predicting stillbirth (100\%). Also, we found a high specificity and positive predicting value in need for treatment in neonatal intensive care unit.

Arduini and Rizzo studied the test characteristics of the pulsatility index from UA, MCA and RA to predict adverse perinatal outcome in 120 SGA fetuses. ${ }^{13}$ In $46.7 \%$ (56 of 120) of fetuses, there was at least one of the following adverse outcomes: perinatal deaths, cesarean delivery for fetal distress, asphyxia that necessitate admission to the neonatal intensive care unit for more than 48 hours. The author found that UA/MCA PI index ratio was the best test when compared with MCA, UA, and RA PI indices (sensitivity $89 \%$, specificity $94 \%$ ).

\section{DISCUSSION}

In our study of 170 cases, we included cases with risk factors like preeclampsia, IUGR, $\mathrm{BOH}$, postdated pregnancy, twin pregnancy. CPI ratio was abnormal in $80 \%$ cases of pre-eclampsia and IUGR. A low index of pulsatility in the middle cerebral artery associated with fetal compromise has been described. ${ }^{19-22}$ Because the MCA/UA ratio incorporates data not only on placental status but also on fetal response, it is potentially more advantageous in predicting perinatal outcome. Doppler data combining both umbilical and cerebral velocimetry provide additional information on fetal consequences of the placental abnormality. ${ }^{23}$ Abnormal MCA/UA PI Doppler ratio is strongly correlated with worse fetal prognosis. In normal pregnancies, the diastolic component in the cerebral arteries is lower than in the umbilical arteries at any gestational age. Therefore, the cerebro-vascular resistance remains higher than the placental resistance and the MCA/UA ratio is greater than 1. The index becomes less than 1 if the flow distribution is in favor of the brain in pathological pregnancies. We observed reduction in placental perfusion and an increase in flow towards the brain. This phenomenon called the brain sparing effect, is supposed to compensate for fetal hypoxia and is associated most of the time with fetal growth retardation with low umbilical artery $\mathrm{pH}$. The cerebrovascular index decreases progressively, as in the normal fetuses so the hypoxia to be compensated by the brain hyperperfusion. ${ }^{24}$

Funding: No funding sources Conflict of interest: None declared

Ethical approval: The study was approved by the Institutional Ethics Committee

\section{REFERENCES}

1. Sibai B, Dekker G, Kupfermine M. Pre-eclampsia. Lancet. 2005;365(9461):785-99.

2. Khan KS, Wojdyla D. Say L. WHO analysis of causes of maternal death: a systematic review. Lancet. 2006;367:1066-74.

3. Satomura S. Ultrasonic Doppler method for the inspection of cardiac function. J Acoust Soc Am. 1957;29:1181-5.

4. Dubiel M, Breborowicz GH, Marsal K, Gudmundsson S. Fetal adrenal and middle cerebral artery in high risk pregnancy. Ultrasound Obstet Gynecol. 2000;16:414-8.

5. Kurjak A, Kupesic S, Zudenigo D. Doppler ultrasound in all three trimesters of pregnancy. Curr Opin Obstet Gynecol. 1994;6:472-8.

6. Arduini D, Rizzo G. Doppler studies of deteriorating growth-retarded fetuses. Current Opinion in Obstetr Gynecol. 1993;5(2):195-203.

7. Hernandez-Andrade E, S cheier M, Dzerega V, Carmo A, Nicolaides KH. Fetal middle cerebral artery peak systolic velocity in the investigation of non-imune hydrops. Ultrasound Obstet Gynecol. 2004;23:442-5.

8. Kassanos D, Siristatidis C, Vitoratos N, Salama lekis E, Creatsas G. The clinical significance of Doppler findings in fetal middle cerebral artery during labor. J Obstet Gynecol Reprod Biol. 2004;23:442-5.

9. Hershkovitz R, Kingdom JCP, Geary M, Rodeck $\mathrm{CH}$. Fetal cerebral blood flow redistributionin late gestation: identification of compromise in small fetuses with normal umbilical artery Doppler. Ultrasound Obstet Gynecol. 2000;15:209-212.

10. Vyas S, Nicolaides KH, Bower S, Campbell S: Middle cerebral artery flow velocity waveforms in fetal hypoxaemia. $\mathrm{Br} \mathrm{J}$ Obstet Gynaecol. 1990;97:797-803.

11. Baschat AA. Doppler application in the delivery timing of the preterm growth-restricted fetus: another step in the right direction. Ultrasound Obstet Gynecol. 2004;23:111-8.

12. Sterne G, Shields LE, Dubinsky TJ. Abnormal fetal cerebral and umbilical Doppler measurements in fetuses with intrauterine growth restriction predicts the severity of perinatal morbidity. J Clin Ultrasound. 2001;29:146-51.

13. Arduini D, Rizzo G, Romanini C. Changes of pulsatility index from fetal vessels preceding the onset of late decelerations in growth retarded fetuses. Obstet Gynecol. 1992;79:605-10.

14. Arias F. Accuracy of the middle-cerebral-toumbilical- artery resistance index ratio in the prediction of neonatal outcome in patients at high risk for fetal and neonatal complications. Am J Obstet Gynecol. 1994;171:1541-5.

15. Makhseed M, Jirous J, Ahmed MA, Viswanathan DL. Middle cerebral artery to umbilical artery resistance index ratio in the prediction of neonatal outcome. Int J Gynecol Obstet. 2000;71:119-25. 
16. Williams KP, Wilson S. Maternal cerebral blood flow changes associated with eclampsia. Am J Perinatol. 1995;12:189-91.

17. Gramellini D, Folli MC, Raboni S, Vadora E, Merialdi A. Cerebral umbilical Doppler ratio as a predictor of adverse perinatal outcome. Obstet Gynecol. 1992;79:416-20.

18. Cunnigham FG, Gant NF, Leveno KJ, Gilstrap LC, Hauth JC, Wenstrom FD. Hypertensive disorders in pregnancy: In: Seils A, Noujaim SR, Devis K, editors. Williams obstetrics, $21^{\text {st }}$ ed. USA: The McGraw-Hill; 2001: p. 568-9.

19. Madazli R, Uludag S, Ocak V. Doppler assessment of umbilical artery, thoracic aorta and middle cerebral artery in the management of pregnancies with growth restriction. Acta Obstet Gynecol Scand. 2001;80:702-7.

20. Severi FM, Bocchi C, Visentin A, Falco P, Cobellis L, Florio P, et al. Uterine and fetal cerebral Doppler predict the outcome of third trimester small-forgestational age fetuses with normal umbilical artery Doppler. Ultrasound Obstet Gynecol. 2002;19:225-8.

21. Dubiel M, Gudmundsson S, Gunnarsson G, Marsal K. Middle cerebral artery velocimetry as a predictor of hypoxemia in fetuses with increased resistance to blood flow in the umbilical artery. Early Hum Dev. 1997;47:177-84.

22. Seyam YS, Al-Mahmeid MS, Al-Tamimi HK. Umbilical artery Doppler flow velocimetry in intrauterine growth restriction and its relation to perinatal outcome. Int $\mathbf{J}$ Gynaecol Obstet. 2002;77:131-7.

23. Bahado-Singh RO, Kovanci E, Jeffres A, Oz U, Deren O, Copel J, et al. The Doppler cerebroplacental ratio and perinatal outcome in intrauterine growth restriction. Am J Obstet Gynecol. 1999;180:750-6.

24. Rizzo G, Arduini D, Luciano R, Rizzo C, Tortorolo G, Romanini C, et al. Prenatal cerebral Doppler ultrasonography and neonatal neurologic outcome. J Ultrasound Med. 1989;8:237-40.

25. Brar HS, Horenstein J, Medearis AL, Platt LD, Phelan JP, Paul RH. Cerebral, umbilical and uterine resistance using Doppler velocimetry in postterm pregnancy. J Ultrasound Med. 1989;8:187-91.

26. Arduini D, Rizzo G. Prediction of fetal outcome in small for gestational age fetuses: comparison of Doppler measurements obtained from different fetal vessels. J Perinat Med. 1992;20:29.

Cite this article as: Deora R, Gara N. The value of the middle cerebral to umbilical artery doppler ratio in the prediction of neonatal outcome in patients with high risk pregnancy. Int J Reprod Contracept Obstet Gynecol 2017;6:3965-8. 